\title{
PHYSIOGNOMY OF MILITARY OPERATIONS ANSWER TO HYBRID THREATS
}

\author{
Mihai Marcel NEAG \\ “Nicolae Bălcescu" Land Forces Academy, Sibiu, Romania \\ mmneag@yahoo.com
}

\begin{abstract}
The widening of the spectrum, the diversity of forms of manifestation of hybrid threats, the influence of economic, political, diplomatic, informational and psychological aspects, now occupy, more than ever, a very important place in the architecture of military operations, but also the fact that the evolution of technology in the field of communications, informatics and cyber defense led to an exponential increase in the power of information.

The timely and pertinent threat analysis of the hybrid warfare allows military decision-makers to identify, through an elaborate and pragmatic approach, the best solutions for preparing the armed forces for military response operations.
\end{abstract}

Keywords: hybrid threats, combined capabilities, conventional operations, hybrid operations, asymmetric operations

\section{Introduction}

The complexity of the operational environment of future military confrontations, given by the variety of types and forms of manifestation of risks and threats, determines at the level of the military analysts a serious analysis and elaboration of a culture of development of strategic thinking meant to reduce the degree of uncertainty in the military action, adaptation of current operational concepts and integration of new paradigms related to the military phenomenon.

The armed conflict will continue to be provided by the use of conventional military forces, professional armed forces, highly technologically advanced, but - as was the case in the recent clashes and in the ongoing ones - the focus has shifted to the engagement of unconventional forces and asymmetrical (irregular).

This aspect, which greatly diversifies and extends the beach of manifestation and the intensity of threats within the current operational environment, tends to fade the boundaries between armed and non-military confrontation, between a conflict and a nonconflict situation, between the state of peace and the state of war.

Analysis and study of what we call the hybrid war today is a dynamic process that must be permanently correlated with the realities of the battlefield. Analyzing the current conflicts, it is noticed that the methods and tactics they use are not new, but only the form they are wearing is new and adapted to the technological development period.

The emergence and development of highprecision weapons systems and intelligent weapons necessitates a new approach to the issue of the human-technical battle report, because ensuring the functioning of this system imposes additional requirements for the military in order to know the characteristics of the modern fighting equipment and the use procedures in parallel with the continuous development of 
physical and intellectual skills designed to allow efficient use of technology in the most complex situations.

\section{Framework for current and future military operations}

Contemporary military conflicts have highlighted new orientations on the conduct of military actions, characterized by complexity, mobility, dynamism, the use of high technology and almost totally professional forces, integrated actions of all categories of forces and arms.

The complexity of the operational environment of future military confrontations, given by the variety of types and forms of manifestation of risks and threats, determines at the level of the military analysts a serious analysis and elaboration of a culture of development of strategic thinking meant to reduce the degree of uncertainty in the military action, adaptation of current operational concepts and integration of new paradigms related to the military phenomenon. The term "hybrid conflict" / "hybrid war" is used in the military literature to define a military strategy in which conventional warfare, unconventional and asymmetric elements are encountered.

The hybrid model of conflict, related to classic conflict, is a dynamic interaction between hard power and soft power elements. Thus, along with the military dimension, instruments such as political, economic, informational and media tools as well as instruments of cyberwar [1] have been introduced into operations.

The prerequisites for future military operations will be in an open and dissimulated environment, sometimes under the interface of rebellion and separatism, involving various inter-national and multinational forces, using advanced technologies, exploiting political, economic, social and informational opportunities and vulnerabilities. Also, increased force mobility, prompt air support, high-impact capabilities, and information technology will require commanders and command teams to be precise and timely in planning, initiative, and timing in execution.

The armed forces participate in joint actions with other actors operating in the security field, but also with agencies or departments of governments that have economic development or political stability, leading to the neutralization of hybrid threats. This is a reality of the present, but it will also pose a challenge in the future, with the maintenance of an unstable, ambiguous, uncertain and fluid operating environment. At the same time, this is the reason why the physiognomy of future military operations must be reconsidered in the context of the multidimensional operational environment. In this context, "the ground forces provide maneuvering, striking and protective capabilities, capable of achieving the deployment, presence, expansion and continuity of military operations" [2].

Military operations carried out in a hybrid environment will have an integrated, universal and multinational character by correlating and interconnecting maneuvers in all environments, lethal blows across the spectrum of conflict to achieve established effects, non-kinetic (informational, cybernetic, psychological, and media), not only the destruction of the opponent, but the defeat of his will to fight.

In a hybrid operating environment, the importance of planning and executing special operations increases. The basis of the operations of the special operations is the principle of surprise and the high tempo of the actions, allowing the missions and the withdrawal before the opponent can react. In some situations, the operations carried out by special operations forces are designed to hit the critical capabilities of the enemy, including the decisive points, affecting his weight centers and maneuvering approach, his will to fight.

Special attention is given to nonconventional operations at national and multinational level as part of the hybrid 
conflict, where the CBRN threat has escalated, with the possibility of triggering particularly violent conventional conflicts in hostile, unstable and unpredictable areas.

Asymmetric operations, irrespective of their typology, and the actors involved revolutions, interventions, civil war, insurgency, guerrilla, terrorism, organized crime, cyber attacks, CBRN terrorism - are part of the hybrid conflicts and have a complex physiognomy. This type of operation involves the use of unconventional tactics and relatively novel places to attack the opponent. Also, actors who appeal to such tactics often resort to methods that include civil unrest to avoid the numerical, tactical, or technological advantages of an opposing one. [3]

\section{Physiognomy of military operations in the hybrid battle space}

The participation of armed forces in military operations in a hybrid operating environment, leading to the neutralization of specific threats, is a reality of the present, but will also pose a challenge in the future, with the preservation of an unstable, ambiguous, fluid. Politician-military analysts' assessments of the security environment in Europe have changed after the military conflicts in Georgia and Ukraine. "... the volatility of the security environment, the proliferation of terrorism and the migration generated by the situation in the Middle East and North Africa (MENA) represent a real paradigm shift in the area of strategic interest of Romania" [4].

The Doctrine of Allied Operations recommends the use of forces from the earliest stages of the conflict, to limit the effects and to prevent conflicts. We note, at the same time, that the first phases of the conflict are not to prevent it.

We thus deny that the North Atlantic Alliance has a reactive attitude towards engaging in conflict resolution. At the same time, in recent years, from the doctrinal and political point of view, the US has adopted a preemptive attitude that allows it to attack first in order to obtain the initiative under the imminence of attacking the enemy, invoking Article 51 of the UN Charter. Preemptive attitude is taken to win the initiative if there are clear threats to its own security.

The preemptive attitude is different from the preventative attitude that refers to the execution of some actions, generally striking, to prevent the adversary from acting adversely. The UN Charter does not provide legal support for preventive or preemptive actions. However, Article 51 of the UN Charter - the right to self-defense, is speculated by experts in the field of the Law of War, for use as a reference for executing preemptive strikes."Nothing in this Charter shall prejudice the inherent right of individual or collective self-defense in the event of an armed attack against a Member of the United Nations until the Security Council has taken the necessary measures for the maintenance of international peace and security. Measures taken by Members in the exercise of this right of self-defense will be immediately brought to the attention of the Security Council and will in no way affect the power and duty of the Security Council, under this Charter, to undertake at any time the actions it deems necessary for the maintenance or restoration of international peace and security " [5].

The threats faced by land forces will be hybrid, innovative, adaptive, taking advantage of the technological advantage that the current environment offers. The multitude of potential actors on the scene of the operational environment will carry out their actions in a conventional and unconventional manner, engage adaptive and asymmetrical combinations of traditional, asymmetrical techniques, tactics and procedures, and criminal elements, using traditional military capabilities in new and old ways.

Due to the complexity of the hybrid threats and the fact that in these cases the aggressor is often not recognized, the difficulty of 
triggering the specific response to the armed struggle is outlined. However, in combating hybrid threats and threats, combat operations or armed struggle are the most powerful deterrent, response and action to restore and maintain operational environment control. This type of operation involves direct confrontation, combat action between conventional and / or unconventional forces, on a scale and with varying frequency and intensity. They must have an integrating character, fully correlated with the actions of the other instruments of power, in a coherent and flexible interinstitutional framework.

High-technology conventional operation, can be conceived after two hypothetical scenarios: the first involves confronting a lower military force from a technological, decisional, actional point of view and resources under conditions of excessive disproportionality or disimetry; and the second, which involves confronting an adversary that creates a balance that can respond strongly to several kinds of Alliance actions, may even have initiative and superiority in several confrontational environments.

Under the first scenario, of the power dissimetry, the operations of the technologically and actively superior part will begin in the cybernetic and electronic environment, by neutralizing the opponents' networks by blocking the communications between the echelon horizontally and vertically. The reaction of the actor in military inferiority to counteract these actions can be taken into account only in the short term but will not affect the conduct of operations: anti-aircraft defense and the installation of false targets, loss making and resource generation. The moment of maximum intensity of confrontation may be missing (as happened in the Yugoslav war), it was less intense (like the wars in Iraq and Georgia), or in the case of a highly motivated force, it could turn from a disproportionate conflict to an asymmetric one .
The second hypothetical scenario is to confront military forces with similar military capabilities that can create at least temporary balances in confrontational environments. The manifestation of this confrontation can be unfolded between the two military forces or through a series of interpositions, but using the capabilities and support of the sponsoring states.

Conflict in the cybernetic and electronic environment will block communications and data transmissions of combat forces at certain times and sectors, which will lead to the introduction of other capabilities and categories of forces into operation. The rapid expansion of the conflict across the operational area, involving all the available technology as well as the extensive hybrid capabilities, will generate a violent conflict with a high consumption of both resources and energy from both forces and limited in time. Due to the complexity of the operational environment, military actions will take place across the spectrum of conflict - offensive, defensive, stability and intermediate - in order to achieve the objectives.

Offensive operations against hybrid risks and threats require a comprehensive approach and must be planned and deployed simultaneously using conventional, unconventional, asymmetric, informational, cyber, political, diplomatic, economic and social means. The offensive as the decisive form of conducting the armed struggle is also "the main form of the army's fighting actions, consisting in taking the initiative of operations aiming at destroying the enemy force and conquering the land it occupies" [6].

Success is driven by the achievement and maintenance of the initiative in all confrontational environments, the exploitation of any opportunity in the operational situation, the speeding action, the provision and support of the commanders' initiative at all levels, the leadership through missions and objectives. After 2014, especially at the strategic level 
some measures have been taken with defensive character, being considered part of the Alliance's military response to the hybrid threat in the East. On February 5, 2018, NATO Secretary General Jens Stoltenberg stated that "NATO is facing ever more challenges: a much more unpredictable Russia, uncertainty and terror near our borders, as well as a wider expansion of weapons of mass destruction" [7].

At the tactical level, defensive actions are meant to counteract the opponent's offensive, make him lose the initiative, even temporarily turn to defensive action, cause him to lose, and not achieve his goal. The whole range of defensive actions must be made in a pro-active attitude, effective defense is rarely passive. Under the conditions of hybrid risks and threats, the capability capability at a given moment may be favorable to the opponent, which will require forces to pool forces to cope with the opponent and his actions. Defender's actions allow him to save money, resources and resources that over time can lead to an advantage for the decisive moment. Offensive reactions should not be missed in defensive operations, adverse forces must be brought to the advantage of losing their capabilities. "If our troops are in inferiority, temporarily prevent the enemy from taking the initiative. You may then be able to take advantage of a weak point. You will then mobilize all your energies and pursue your victory firmly"[8].

The focus of the attacker's combat power on key defense points can be countered by operations in the informational environment, the information, psychological or physical counterattack executed in the area of strategic interest (far beyond the scope of operations). These offensive actions for defense against critical elements or capabilities can stop or slow the pace of operations and even create an operational advantage.
Evolutionally, after completing combat operations, security operations or stabilization facilitation will be performed to return to a state of normality. If in combat operations the ultimate goal is victory, defeat of the opponent, direct confrontation of forces, and intense action and violence. At the post-conflict stage, the ultimate goal of security operations or facilitating stabilization, is to end the conflict, neutralize the causes that have led to its emergence.

Among the offensive actions we mention are the disarmament, demobilization and reintegration process (DDR), as well as the cordon and search / research, and among the defensive actions the control of the crowd, ensuring the security of the place and the columns. "Disarmament, demobilization and reintegration of former combatants - DDR is an essential process for the return to peace of areas affected by armed conflicts. The process is materialized through a set of activities organized and implemented in a certain area by a multitude of governmental, nongovernmental and international actors to collect weapons and ammunition from belligerents, remove military personnel, prepare and its introduction into the socioeconomic life cycle of civilian communities" [9].

Security in the operation area is a generic task in stability and support actions and focuses on limiting any hostile action directed against military or civilian objectives, private property, or individuals. Conventional military operations must be analyzed in terms of the type of threat, the technological level of the actors involved to infer, compared to their own (national or multinational) forces, the qualitative ratio in which the actions will be planned, prepared and executed in conditions of superiority , technological equilibrium or inferiority, information, decision-making and action.

In this context, we appreciate that conventional military operations carried out in a hybrid environment will have an 
integrated, universal and multinational character by correlating and interconnecting maneuvers in all environments, lethal blows across the spectrum of the conflict to achieve the established effects, non-kinetic (informational, cybernetic, psychological, and media) actions, focusing not on destroying the opponent but on defeating his will to fight.

At the same time, I believe that hightechnology conventional military operations do not end suddenly, even if the strategic goals initially set are achieved, but they are very much extended to the transition phase, which translates from the violent confrontation to the normality, the aspects related to the presence of the population conflict area and support for refugees and evacuees.

In conclusion, the complexity of highly technologically advanced conventional military operations that precede or follow other types of operations planned and carried out in a hybrid environment by integrating capabilities, technologies and resources to deliver the operational advantage, maintaining the initiative, overtaking the opponent, and the achievement of the desired objectives, effects and final state.

Unconventional operations are specific to forces for special operations or for forces using nuclear weapons. Contrary to the meaning of conventional and unconventional words, conventional weapons are not the subject of any convention, but unconventional weapons are. From the category of weapons that are forbidden to use by international conventions are weapons of mass destruction, chemical, biological and radiological and therefore their use is an aspect of unconventional operations.

According to NATO's doctrinal framework, the main missions of Special Forces (SOF) missions are "military assistance, special research and direct action"[10]. In US Doctrine, missions include the following main activities: "direct action, special research, weapons of mass destruction, antiterrorism, unconventional warfare (UW), internal defense against foreign actions, assisting security forces, rescuing and recovering hostages, counterinsurgency, humanitarian assistance abroad, military intelligence operations and civilian operations (CIMIC) "[11]. Today, particular attention is paid to unconventional operations at national and multinational level as part of the hybrid conflict, where the CBRN threat escalated, with the possibility of triggering particularly violent conventional conflicts in hostile, unstable and unpredictable areas.

SOFs are strategic level capabilities that are committed to achieving strategic and operative goals. Special operations differ from conventional operations primarily by using ingenious action techniques, then by high degree of political risk and operating methods. The basis of the SOF's actions is the principle of surprise and the high tempo of action, allowing missions and retreat before the opponent can react. Special capabilities for special operations forces offer the possibility of using them throughout the spectrum of future conflicts as part of collective defense and crisis response operations in peacetime for solving politically sensitive issues. Also prior to military operations conducted in a hybrid environment, the use of SOF may be part of the preemptive actions undertaken to prevent escalation of crises to the conflict.

Asymmetric operations carried out under hybrid-type risks and threats, based on the comprehensive approach concept, aim at neutralizing sources of instability, eliminating underdevelopment and faulty management. Asymmetric operations have a pronounced civilian-military character, due to the fact that the achievement of the desired final state can only be achieved by the joint action of civilian and military power tools. By planning and execution, they must combine offensive, defensive, and stability tactical tactics. By way of planning and execution these must 
combines at the tactical level offensive, defensive and stability actions.

Offensive actions in asymmetric operations, executed under hybrid-type threats and threats, are not limited to offensive action in the physical environment or information operations. Actions are geared towards gaining population support, infrastructure and economy development. Defensive actions are designed to limit the effects of the opponent's actions on the civilian population, the armed forces, the other actors in the operations area and the infrastructure. The defensive character is predominantly reactive and occurs as a result of the actions of the opponent.

Asymmetric operations, irrespective of their typology and the actors involved revolutions, interventions, civil war, insurgency, guerrilla, terrorism, organized crime, cyber attacks, CBRN terrorism - are part of hybrid conflicts and have a complex physiognomy aimed at compensating conventional and technological superiority of the opponent by using atypical tactics, techniques and procedures that dominate terror and violence, prolonging the conflict as much as possible, and achieving goals aimed at destabilizing political leadership, intimidating and influencing public opinion. Hybrid operations should be regarded as confrontations of the armed forces with a state or non-state enemy using conventional, unconventional, asymmetric, informational, cybernetic, diplomatic, economic and psychological means in the physical and cognitive environment within the legal framework internationally or externally, exploiting all of its own vulnerabilities to create a complex global effect.

In hybrid operations, actions in support of governance, reconstruction and development are essential from the very beginning of the adversary's attempt to destabilize the rule of law. Discretization of the political class, economic destabilization to reduce living standards, incitement to protests, worsening ethnic tensions, and information campaigns are actions that are part of the hybrid arsenal of the opponent. Their countermeasures can be done through support actions in the field of economic development, achieving a sustainable basis for the rule of law, a stable, secure and prosperous environment in which human rights are respected.

\section{Conclusions}

No matter how much we try in analytical processes, in textbooks or in research studies or in research work, we can not reduce the fight / battle to a mere act of aggression, nor embrace the idea of phenomenon, and this goes away from the idea of complexity the preliminaries and the importance of the political and military consequences. The struggle / battle calls for action all that science and the time culture has produced, so it is and remains a complex event.

Analysis of the effectiveness of the actions / operations must always remain in the commanders' attention. Future military operations will no longer be intended for missions, but to achieve objectives, and most of the time these objectives will no longer be strictly military. In such a conception, the military will have to work with non-military entities to achieve the desired final state. Hybrid military operations, also referred to as multimodal, multidimensional, ambiguous or mosaic operations, include a wide range of conventional, unconventional, asymmetric, informational, cyber, psychological, and media actions along with political, diplomatic, cultural and religious affairs, aimed at achieving complex political and military goals.

Future military operations will be conducted under the conditions of multidimensionality of the confrontational environment, involving both sides civil and military actors, and their actions will have effects almost instantaneously at global level.

The high technology of operations, the precision of weapon systems, the growth of transport capabilities, the capabilities of communications, cybernetic and cyber 
defense equipment integrated with control command systems will allow bold and well synchronized actions, highlight the importance of man in driving and execution of the actions and will provide an adequate degree of flexibility to address the risks and threats of the hybrid type.

\section{References}

[1] Oana IORDAN, Hybrid war and cyber attacks, July 17, 2017, http://intelligence.sri.ro/ razboi-hibrid-si-atacuri-cibernetice/, accessed on 27.03.2018.

[2] Romania's Military Strategy, Modern Armed Forces for a Strong Romania in Europe and the World, of September 28, 2016, pp.14.

[3] Dr. Petre DUȚU, Asymmetric threats or hybrid threats: Conceptual delimitations for the foundation of national security and defense, National Defense University Publishing House „Carol I”, Bucharest, 2013, pp.29.

[4] Romania's Military Strategy of September 28, 2016, Modern Armed Forces for a Strong Romania in Europe and the World, consulted on $\mathrm{http}: / / \mathrm{www} . m o n i t o r u l j u r i d i c . r o / a c t / s t r a t e g i a-m i l i t a r-a-r o m-n i e i-d i n-28-s e p t e m b r i e-2016-$ for-e-armate-moderne-pentru-o-rom-nie-puternic-n-europa-i-n-lume-emitent182367.html, accessed on 28.02.2018.

[5] United Nations Charter, consulted on the sitehttps://ro.wikisource.org/wiki/Cart a Organiza\%C8\%9Biei_Na\%C8\%9Biunilor_Unite, accessed on 28.02.2018.

[6] Dex.ro, The explanatory dictionary of the Romanian language,consulted onhttp://www.dex.ro/ofensiva, accessed on 28.02.2018.

[7] Marian Avram, Mediafax, Jens Stoltenberg, NATO Secretary General, asks NATO member states to honor their military spending commitments, consulted onhttp://www.zf.ro/business-international/jens-stoltenberg-secretarul-general-al-natocere-statelor-membre-nato-sa-respecte-angajamentele-de-crestere-a-cheltuielilor-militare16972615, accessed on 28.02.2018.

[8] Sun Tzu, The Art of War,Antet Publishing House, Bucharest, 2012, p. 42.

[9] Valerică CRUCERU, Disarmament, demobilization and reintegration of former combatants- DDR. General Concept and International Engagement,Bulletin of the National Defense University,,Carol I-, nr. 1 / 2014, p.53.

[10]AJP-3.5 Allied Joint Doctrine for Special Operations, Edition A Version 1, NATO Standardization Agency, December 2013, p. 1-1.

[11]Jp3-05 Special Operations, 16.07.2014, p. IV-1 - 5. 